\title{
Atypical hand, foot, and mouth disease associated with coxsackievirus A6 infection, Edinburgh, United Kingdom, January to February 2014
}

C Sinclair ${ }^{1}$, E Gaunt ${ }^{2}$, P Simmonds², D Broomfield ${ }^{3}$, N Nwafor ${ }^{3}$, L Wellington ${ }^{4}$, K Templeton ${ }^{5}$, L Willocks ${ }^{4}$, O Schofield $^{1}$, H Harvala (heli.simmonds@hotmail.com) ${ }^{2,5}$

1. Department of Dermatology, Lauriston Building, Edinburgh, United Kingdom

2. Infection and Immunity, Roslin Institute, University of Edinburgh, United Kingdom

3. Royal Hospital for Sick Children, Edinburgh, United Kingdom

4. Public Health and Health Policy, Waverley Gate, Edinburgh, United Kingdom

5. Specialist Virology Centre, Royal Infirmary Edinburgh, United Kingdom

Citation style for this article:

Sinclair C, Gaunt E, Simmonds P, Broomfield D, Nwafor N, Wellington L, Templeton K, Willocks L, Schofield O, Harvala H. Atypical hand, foot, and mouth disease associated with coxsackievirus A6 infection, Edinburgh, United Kingdom, January to February 2014. Euro Surveill. 2014;19(12):pii=20745. Available online: http:// www.eurosurveillance.org/ViewArticle.aspx?Articleld=20745

In January to February 2014,16 hand, foot and mouth disease (HFMD) cases were identified in Edinburgh, United Kingdom. All presented with atypical features, with most $(n=13)$ resembling eczema herpeticum or chickenpox. Coxsackievirus A6 (CV-A6) was identified in all the typed cases $(n=11)$. As atypical forms of HFMD associated with CV-A6 are likely to emerge throughout Europe, clinicians should be alert to unusual clinical presentations of HFMD and virologists aware of effective diagnostic testing and enterovirus typing methods.

\section{Identification of hand, foot, and mouth disease cases in Edinburgh}

Eight patients with rashes and fever were identified by dermatology, paediatric and virology services in Edinburgh, United Kingdom (UK), during January 2014. The first four cases clinically resembled eczema herpeticum (Figure 1) and were identified in previously healthy children under the age of 2 years. They all presented with fever (over $37.5^{\circ} \mathrm{C}$ ), lethargy and poor appetite. An erythematous papular rash rapidly progressed, affecting the face, trunk and limbs, involving over $10 \%$ of the body surface area. This was followed by development of vesicles and bullae; one child also developed erythema multiforme. All four children were hospitalised and initially treated with intravenous aciclovir, based on a presumptive diagnosis of severe, disseminated herpes simplex virus (HSV) infection. Papular eruptions lasted around two weeks. Vesicle fluid specimens taken from these individuals were negative for HSV and varicella zoster virus, but positive for enterovirus (EV) RNA [1], confirming the diagnosis of atypical hand, foot and mouth disease (HFMD).

The remaining four patients diagnosed with HFMD in January and a further eight in February also presented with atypical symptoms; four of them clinically resembled eczema herpeticum and five were suspected of having chickenpox. Molecular typing [2] identified coxsackievirus A6 (CV-A6) in all 11 of the typed 16 cases, including the first four.

\section{Background}

HFMD is an acute febrile infection characterised by vesicular exanthema on the hands, feet and oral mucosa, typically occurring in children under the age of 5 years [3]. It is most commonly caused by CV-A16 and $E_{71}$ within the species $E V-A$, members of the virus family Picornaviridae in the genus Enterovirus [3]. Since 2008, HFMD outbreaks in Finland and France have also been associated with other members of species $A$ enteroviruses, including CV-A10 and CV-A6 [4-6]. HFMD associated with CV-A6 infection has been described as atypical: vesiculous and bullous lesions are often generalised and more widely distributed, including dorsal sides of hands and feet, calves and trunk [7].

There are no published data available on the incidence of HFMD in Scotland or the rest of the UK; there is no active public health surveillance for HFMD and it is not a notifiable infection. Whereas CV-A16, EV71 and CV-A6 have been occasionally detected in clinical samples [8], CV-A6 has been known to circulate in Scotland since 2010 , based on our previous environmental surveillance [9].

\section{Retrospective study of cases of atypical} hand, foot and mouth disease in Scotland A review of virology laboratory data from the Specialist Virology Centre in Edinburgh showed that 55 EV RNApositive cases of clinically suspected HFMD were identified in Edinburgh between January 2010 and February 2014, most of whom $(n=39)$ were diagnosed following admission to hospital; the rest $(n=16)$ were diagnosed by a general practitioner (Figure 2 ). 


\section{FIGURE 1}

Child with atypical hand, foot and mouth disease associated with coxsackievirus A6 infection, Edinburgh, United Kingdom, January 2014

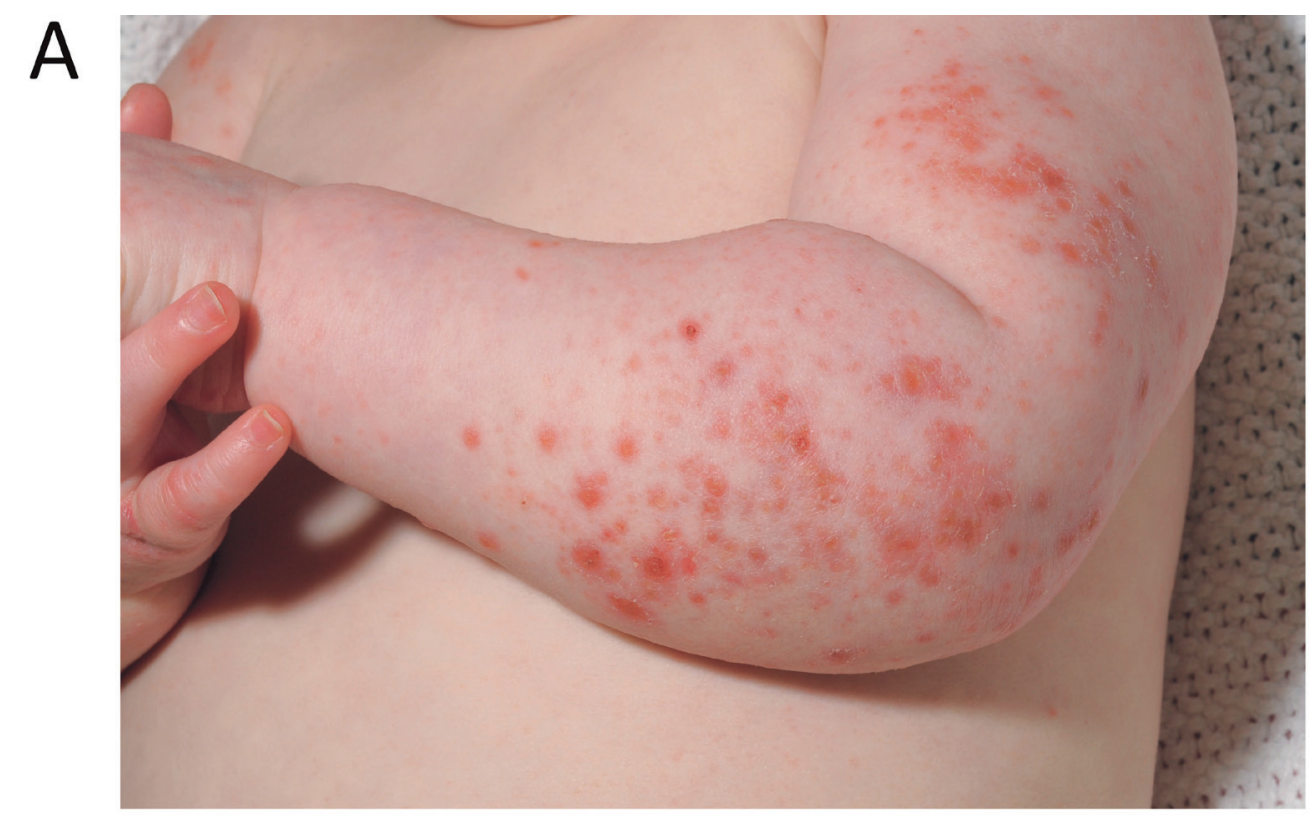

\section{B}
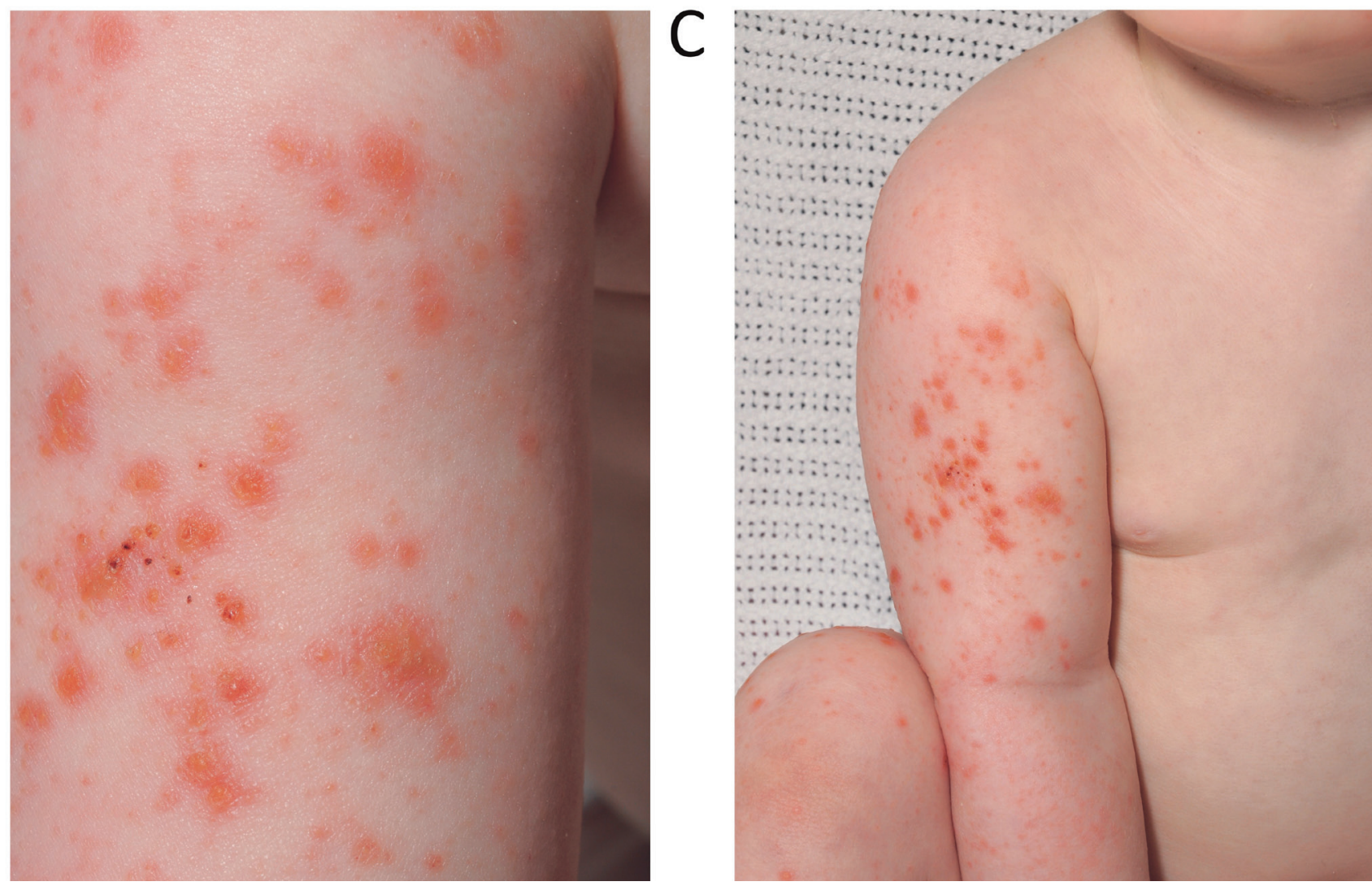

(a)

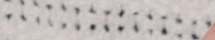

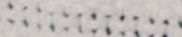

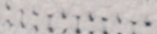

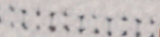

…2:

ax.......

:.:.:.:.:

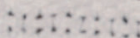

::2::2:::

:::::::t:

in:as:

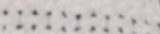

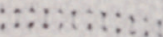

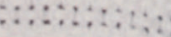

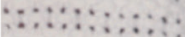
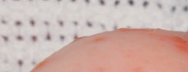

.

. 
Hand, foot and mouth disease diagnoses confirmed by enterovirus PCR, Edinburgh, United Kingdom, January 2010February $2014(n=55)$

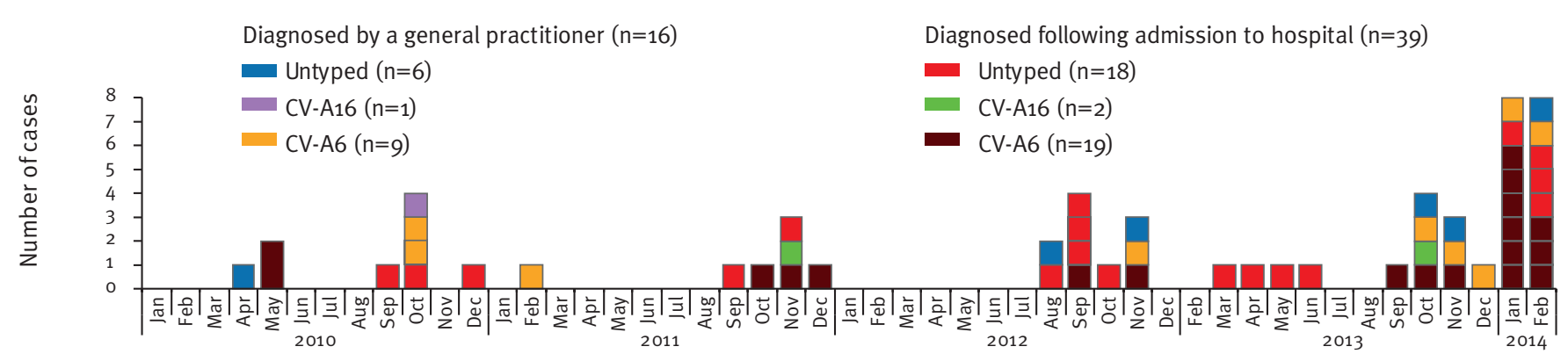

Date

The main aim of this study was to investigate the viral aetiology and presentations of HFMD. All clinically suspected cases of HFMD from whom EV was detected in a vesicle swab sample were included in this study. Cases were defined as having atypical HFMD if CV-A6 was directly identified from the vesicle fluid obtained.

Almost half (25/55) of the EV-positive cases of HFMD were identified within the last six months (September 2013 to February 2014). EV RNA was detected in vesicle fluid specimens by real-time RT-PCR targeting the 5'untranslated region [1]. For genotyping, the VP4 gene was amplified and sequenced as previously described [2]. The VP1 region was amplified using a newly designed nested primers specific for CV-A6 (outer sense: GARGCTAACATYATAGCTCTTGGAGC; inner sense: GACACYGAYGARATY CAACAAACAGC; inner antisense: CGRTCRGTTGCAGTGTTWGTTATTGT; outer antisense: CCYTCATARTCHGTGGTGG TTATGCT).

CV-A6 was identified in 29 of the 42 samples typed to date (two samples were typed from one case, otherwise one sample per case): 10 older samples were not available and typing of four newer samples is still ongoing. Three samples were shown to be CV-A16: two of the patients with CV-A16 infection presented with typical HFMD, whereas the third was suspected of having measles.

Most cases (11/16) of atypical HFMD diagnosed since 2013 clustered closely together by phylogenetic analysis of the VP1 gene by neighbour joining [10] (Figure 3), indicating the introduction of a new CV-A6 strain into the UK. Previous cases clustered separately, as did a CV-A6 variant recovered from a cerebrospinal fluid sample from a patient with suspected meningitis in 2007 [8].

\section{Clinical picture and seasonality}

Of the 55 EV RNA-positive individuals with clinically suspected HFMD identified in our study, 33 presented with atypical symptoms. Eruptions observed in areas of previous eczematous dermatitis, including extremities and the trunk, led to initial clinical diagnoses of eczema herpeticum in 14 of the 33 patients with atypical HFMD, consistent with previous reports describing this disease entity as eczema coxsackium [7,11,12]. The remaining 19 of the 33 patients with atypical symptoms were clinically suspected as having chickenpox. In previous study, cutaneous manifestations of CV-A6 -associated atypical HFMD have resembled chickenpox, with vesicles reported to crust in $65 \%$ of patients between November 2011 and February 2012 in the United States [13].

In our study, 39 of the 55 EV infections occurred in children under the age of 3 years (Figure 4). One case required treatment in an intensive therapy unit and two were shown to have been systemically infected, with detection of viraemia by PCR. Of the 55 cases, seven were adults aged 30-40 years; 31/55 were male.

In contrast to typical HFMD outbreaks, which occur in the summer and early autumn [3], we saw a cluster of cases $(n=24)$ between October 2013 and February 2014. This is consistent with a previous study from the United States, in which atypical cases of HFMD caused by CV-A6 were seen between November 2011 and February 2012 [13].

\section{Discussion}

The number of cases presenting with atypical HFMD and potentially attributable to CV-A6 is likely to be a considerable underestimate of the actual number since surveillance data from Scotland and elsewhere in Europe is limited to EV-infected individuals admitted to hospitals $[6,9]$. Samples from most cases presenting to general practitioners would not be sent for virological investigation (such investigations are optional) and cases would have probably remained undiagnosed, misdiagnosed or unreported. However, the scale of two nursery outbreaks of HFMD in Edinburgh at the 


\section{FIGURE 3}

Phylogenetic analysis of complete VP1 sequences of 25 coxsackievirus A6 variants detected in 24 cases of atypical hand, foot and mouth disease ${ }^{\mathrm{a}, \mathrm{b}}$, Edinburgh, United Kingdom, January 2010-February 2014

- Vesicle swab, 2013-2014

- Vesicle swab, pre-2013

- CSF sample, 2007

o Other CV-A6, >2\% divergent

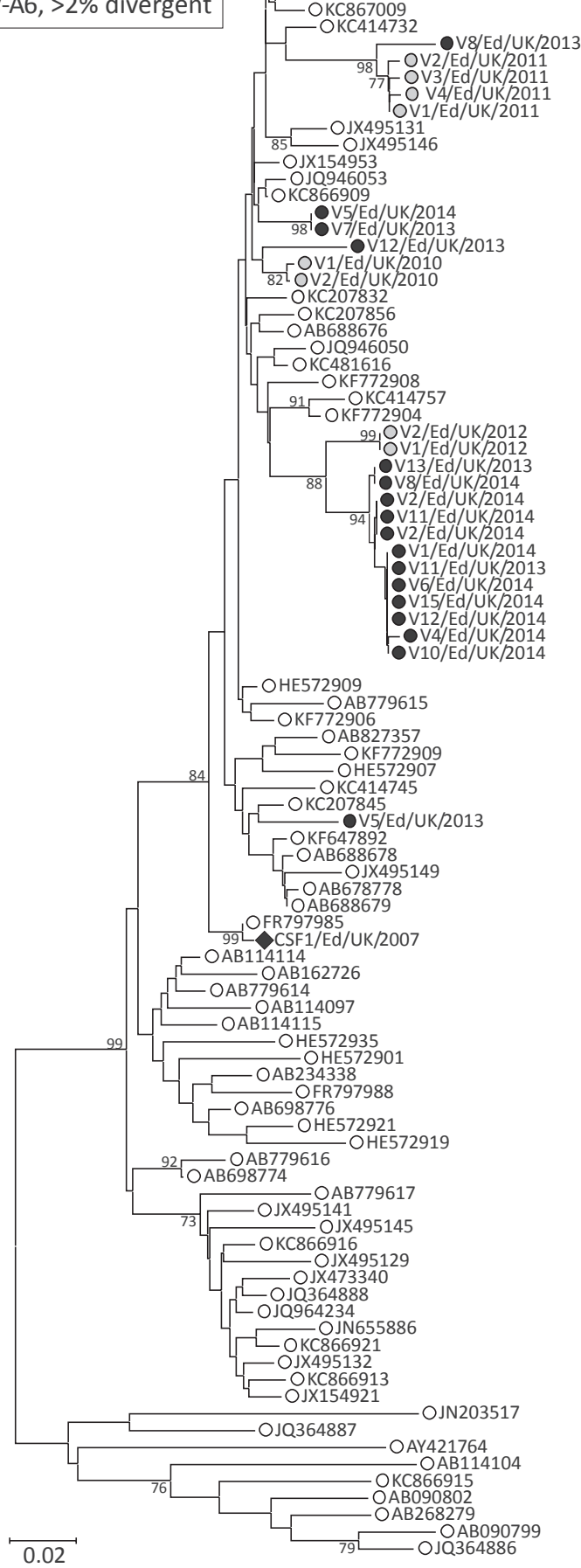

CSF: cerebrospinal fluid; CV: coxsackievirus.

The tree was constructed by neighbouring using maximum composite likelihood distances [10]; the dataset was bootstrap resampled 100 times to estimate robustness of groupings; values of $70 \%$ or greater shown. All available sequences of CV A6 in GenBank, downloaded 10 March 2014, were also included ( $>70 \%$ complete; $>2 \%$ divergent from each other).

a One patient had two samples sequenced, marked twice in the tree as V2/Ed/UK/2014; one of them originated from blood and the other from vesicle fluid.

b The remaining four cases were typed based on the VP4 sequences and were thus not included in this analysis.

\section{FIGURE 4}

Enterovirus-positive hand, foot and mouth disease

diagnoses in Edinburgh, United Kingdom, January 2010February $2014(n=55)$

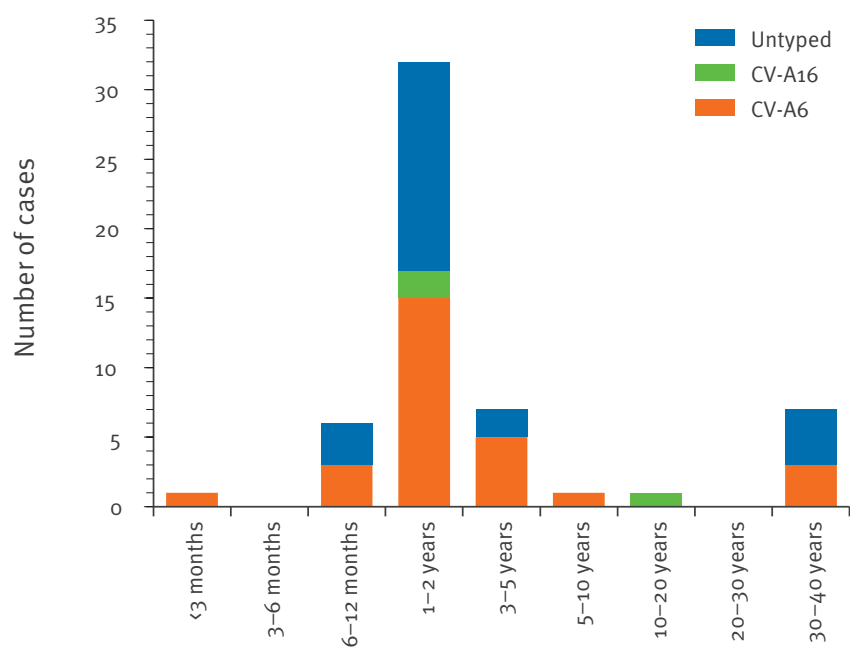

Age at presentation

CV: coxsackievirus.

The majority of diagnoses $(n=39)$ have been seen in children under the age of 3 years.

beginning of 2014 , with $15 / 45$ and $7 / 40$ children under age of 4 years affected, led to notification of the local public health team (data not shown), providing some indication of the extent of its spread in the community. However, these outbreaks were not investigated further and the infections were not laboratory confirmed. These outbreaks, together with the clinical cases reported here since 2010, suggest a change in the clinical severity of CV-A6 infections over the last few years. While CV-A6 clearly circulates locally (being identified as the second most common species A EV in sewage surveillance in Edinburgh in 2010 [9], only one CV-A6 infection (an infant aged under 3 months with meningitis) was identified through routine typing of referred samples during the five years before 2010 [8].

To date, HFMD outbreaks associated with CV-A6 infection have been documented from four countries of the World Health Organization European Region: Finland $[4,5]$, France [6,14], Spain [15] and Israel [16]. However, large outbreaks have also been described in Asia [1719] and the United States [11,13]. The cases of HFMD associated with CV-A6 infection described here clinically resembled HFMD infections caused by emerging CV-A6 in the United States since 2012 [7,11-13] and Japan in 2013 [20], while other reported HFMD outbreaks caused by CV-A6 were associated with onychomadesis one to two months after onset of the initial symptoms $[4,17,18]$. It remains to be seen whether our patients develop nail loss. 
To the best of our knowledge, this is the first report of CV-A6 infections associated with HFMD in the United Kingdom. Our findings provide evidence of a recent change in severity and clinical presentations of CV-A6 infections in Edinburgh that match reports from elsewhere $[7,13,14,20]$. CV-A6 infections are underdiagnosed as a result of lack of routine surveillance at the community level and also atypical presenting symptoms and signs. Awareness of the potential clinical extent and variability of this atypical form of HFMD should help to avoid confusion with other skin conditions such as eczema herpeticum and chickenpox. In addition, increasing awareness will help to improve laboratory diagnosis and management of infected children.

When there are institutional outbreaks, additional information regarding atypical HFMD might be required to educate staff and families, and also remind them of appropriate contact precautions for children in nappies. EV PCR testing of vesicle fluid should be recommended in cases where the diagnosis is clinically doubtful, and focused, community-based surveillance as well as formal case investigations should be considered.

\section{Acknowledgments}

We are grateful to the family for allowing us to use the photographs of their child. We would also like to thank all the clinicians and laboratory members involved.

\section{Conflict of interest}

None declared.

\section{Authors' contributions}

Heli Harvala planned the study, analysed the data and wrote the manuscript. Catriona Sinclair and Olivia Schofield participated in patient care as expert dermatologists, whereas Dylan Broomfield and Nke Nwafor were the pediatricians and Heli Harvala and Kate Templeton the medical virologists involved in the diagnosing of the cases. Eleanor Gaunt and Peter Simmonds did the virus sequencing. Louise Wellington and Lorna Willocks provided the data from NHS Lothian Health Protection. All the authors contributed to manuscript.

\section{References}

1. Bennett S, Harvala H, Witteveldt J, McWilliam Leitch EC, McLeish N, Templeton K, et al. Rapid simultaneous detection of enterovirus and parechovirus RNAs in clinical samples by one-step real-time reverse transcription-PCR Assay. J Clin Microbiol. 2011; 49(7):2620-4. http://dx.doi.org/10.1128/ JCM.02445-10

2. Wisdom A, Leitch EC, Gaunt E, Harvala H, Simmonds P. Screening respiratory samples for detection of human rhinoviruses (HRVs) and enteroviruses: comprehensive VP4 VP2 typing reveals high incidence and genetic diversity of HRV species C. J Clin Microbiol. 2009;47(12):3958-67. http://dx.doi. org/10.1128/JCM.00993-09

3. McMinn P. An overview of the evolution of enterovirus 71 and its clinical and public health significance. FEMS Microbiol Rev. 2002;26(1):91-107. http://dx.doi.org/10.1111/j.1574-6976.2002. tboo601.x

4. Osterback R, Vuorinen T, Linna M, Susi P, Hyypiä T, Waris M. Coxsackievirus A6 and hand, foot, and mouth disease, Finland.
Emerg Infect Dis. 2009;15(9):1485-8. http://dx.doi.org/10.3201/ eid1509.090438

5. Blomqvist S, Klemola P, Kaijalainen S, Paananen A, Simonen $M L$, Vuorinen T, et al. Co-circulation of coxsackieviruses A6 and $A_{10}$ in hand, foot and mouth disease outbreak in Finland. J Clin Virol. 2010;48(1):49-54. http://dx.doi.org/10.1016/j. jcv.2010.02.002

6. Mirand A, Henquell C, Archimbaud C, Ughetto S, Antona D Bailly JL, et al. Outbreak of hand, foot and mouth disease/ herpangina associated with coxsackievirus $A 6$ and $A_{10}$ infections in 2010, France: a large citywide, prospective observational study. Clin Microbiol Infect. 2012;18(5):E110-8. http://dx.doi.org/10.1111/j.1469-0691.2012.03789.x

7. Feder HM Jr, Bennett N, Modlin JF. Atypical hand, foot and mouth disease: a vesiculobullous eruption caused by Coxsackie virus A6. Lancet Infect Dis.2014:14(1):83-6. http:// dx.doi.org/10.1016/S1473-3099(13)70264-0

8. Leitch EC, Harvala H, Robertson I, Ubillos I, Templeton K, Simmonds P. Direct identification of human enterovirus serotypes in cerebrospinal fluid by amplification and sequencing of VP1 region. J Clin Virol. 2009;44(2):119-24. http://dx.doi.org/10.1016/j.jcv.2008.11.015

9. Harvala H, Calvert J, Nguyen DV, Gadsby N, Molyneux $\mathrm{P}$, Templeton K, et al. Comparison of enterovirus and parechovirus surveillance using diagnostic clinical samples and environmental sampling in Scotland. Euro Surveill. Forthcoming 2014.

10. Tamura K, Stecher G, Peterson D, Filipski A, Kumar S. MEGA6: Molecular Evolutionary Genetics Analysis version 6.0. Mol Biol Evol. 2013;30(12):2725-9. http://dx.doi.org/10.1093/molbev/ mst197

11. Flett K, Youngster I, Huang J, McAdam A, Sandora TJ, Rennick M, et al. Hand, foot, and mouth disease caused by coxsackievirus A6. Emerg Infect Dis 2012; 18: 1702-5. http:// dx.doi.org/10.3201/eid1810.120813

12. Mathes EF, Oza V, Frieden IJ, Cordoro KM, Yagi S, Howard R, et al. "Eczema coxsackium" and unusual cutaneous findings in an enterovirus outbreak. Pediatrics. 2013;132(1):e149-57. http:// dx.doi.org/10.1542/peds.2012-3175

13. Centers for Disease Control and Prevention (CDC). Notes from the field: severe hand, foot, and mouth disease associated with coxsackievirus A6 - Alabama, Connecticut, California, and Nevada, November 2011-February 2012. MMWR Morb Mortal Wkly Rep. 2012;61(12):213-4.

14. Hubiche T, Schuffenecker I, Boralevi F, Léauté-Labrèze $C$, Bornebusch L, Chiaverini C, et al. Dermatological spectrum of hand, foot, and mouth disease from classical to generalized exanthema. Pediatr Infect Dis. J 2014;33(4):e92-8. http:// dx.doi.org/10.1097/INF.0000000000000120

15. Montes M, Artieda J, Pi-eiro LD, Gastesi M, Diez-Nieves I, Cilla G. Hand, foot, and mouth disease outbreak and coxsackievirus A6, northern Spain, 2011. Emerg Infect Dis. 2013;19(4). http:// dx.doi.org/10.3201/eid1904.121589

16. Ben-Chetrit E, Wiener-Well Y, Shulman LM, Cohen MJ, Elinav H, Sofer D, et al. Coxsackievirus A6-related hand foot and mouth disease: Skin manifestations in a cluster of adult patients. J Clin Virol. 2014;59(3):201-3. http://dx.doi.org/10.1016/j. jcv.2013.12.012

17. Wei SH, Huang YP, Liu MC, Tsou TP, Lin HC, Lin TL, et al. An outbreak of coxsackievirus A6 hand, foot, and mouth disease associated with onychomadesis in Taiwan, 2010. BMC Infect Dis. 2011; 11:346. http://dx.doi.org/10.1186/1471-2334-11-346

18. Fujimoto T, lizuka S, Enomoto M, Abe K, Yamashita K, Hanaoka N, et al. Hand, foot, and mouth disease caused by coxsackievirus A6, Japan, 2011. Emerg Infect Dis. 2012;18(2):337-9. http://dx.doi.org/10.3201/eid1802.111147

19. Puenpa J, Chieochansin T, Linsuwanon P, Korkong S, Thongkomplew S, Vichaiwattana P, et al. Hand, foot, and mouth disease caused by coxsackievirus A6, Thailand, 2012. Emerg Infect Dis. 2013;19(4):641-3. http://dx.doi.org/10.3201/ eid1904.121666

20. Yasui Y, Makino T, Hanaoka N, Owa K, Horikoshi A, Tanaka A, et al. A case of atypical hand-foot-and-mouth disease caused by coxsackievirus A6: differential diagnosis from varicella in a pediatric intensive care unit. Jpn J Infect Dis. 2013;66(6):564-6. 